\title{
LA DESTRUCCIÓN DE GRECIA Y EL FUTURO DE EUROPA
}

James K. Galbraith, Welcome to the poisoned chalice.

The destruction of Greece and the future of Europe, New Haven y

Londres, Yale University Press, 2016, 232 pp.

Michael Hudson*

T os artículos y entrevistas de James Galbraith que recoge este Llibro (terminado en octubre de 2015) describen su creciente exasperación por la "troika" - el Banco Central Europeo (BCE) y la burocracia del FMI y de la UE- que se negó a rebajar su exigencia de que Grecia empobreciera su economía en un grado peor que la Gran Depresión. La lucha contra Grecia fue, en resumen, un rechazo de la democracia parlamentaria después de que Syriza, la coalición de partidos de izquierda, ganara las elecciones en enero de 2015 con un programa de oposición a la austeridad y la privatización.

E1 mundo ha visto el resultado: en contraste con la ayuda a los países con regímenes de derecha, el BCE y el FMI apretaron las tuercas financieras en Grecia. El ministro de Finanzas, Yanis Varoufakis -que fue colega de Galbraith en Austin, Texas- le pidió a Galbraith que se reunieran en febrero para ayudar a elaborar una alternativa a la austeridad que se exigía. Eran optimistas, pues pensaban que imperaría la razón: la conciencia de que el programa de los acreedores de "recortar salarios e ingresos sin aliviar las deudas privadas (tales como las hipotecas fijas) solo agravaría la carga de la deuda y llevaría a la gente a la quiebra y a ejecuciones hipotecarias".

Este libro refleja su decepción ante tan desastrosos resultados. A comienzos de junio, un mes antes del referéndum del 5 de julio en el que los electores griegos rechazaron las exigencias del вСЕ-Fмі por

Universidad de Missouri, Kansas City, Estados Unidos, y Universidad de Beijing, China, [Michael.hudson@earthlink.net]. Tomado de Real-World Economics Review 76, 2016, pp. 124-128. Traducción de Alberto Supelano. Se publica con autorización del autor. Fecha de recepción: 7-10-2016, fecha de aceptación: 20-10-2016. Sugerencia de citación: Hudson, M. "La destrucción de Grecia y el futuro de Europa", Revista de Economía Institucional 18, 35, 2016, pp. 345-352. DOI: http://dx.doi.org/10.18601/01245996.v18n35.21. 
un considerable $61,5 \%$, él pensaba que el gobierno caería si capitulaba. "De modo que esta opción no era muy probable". Pero eso fue exactamente lo que ocurrió. Tsipras claudicó y Varoufakis renunció el día siguiente, el 6 de julio.

Una semana antes Galbraith había explicado lo que parecía ser la lógica inherente de la situación: Tsipras "no podía ceder a las condiciones que le exigían. Así la carga recaerá sobre los acreedores, y si eligen destruir un país europeo, el crimen estará en sus manos para que todos lo vean”. Tsipras cedió y la economía griega fue destruida para que la eurozona lograra su propósito imponiendo la insolvencia dentro del euro, no forzándola a retirarse, y dejándola en bancarrota recurriendo a sanciones como las que se emplean contra Cuba o Irán. E1 libro de Galbraith expone la argumentación del fiscal con respecto a lo que siguió. El 3 de mayo le escribió a Varoufakis que no veía "ninguna perspectiva de desarrollo dentro de las estructuras económicas actuales de la eurozona".

Los ensayos del libro presentan la experiencia de Grecia como un ejemplo práctico para otros países que intentan librarse del control financiero de la derecha. El FM у el вСE ni siquiera consideran que su destrucción de la economía griega sea un fracaso. Siguen imponiendo una doctrina de austeridad que demostró ser falaz ya en la década de 1920.

\section{LA CONSTITUCIÓN DE LA UE IMPONE LA DEFLACIÓN DE LA DEUDA Y LA AUSTERIDAD}

Ya en 2010 Galbraith había expresado su "epifanía” de que una solución "basada en el mercado" era un eufemismo de austeridad contra el trabajo y una reversión de la democracia política. "En un sistema financiero exitoso tiene que haber un Estado más grande que cualquier mercado. Ese Estado debe tener el control monetario, como sin deuda lo tiene la Reserva Federal en Estados Unidos”. Eso era lo que muchos europeos esperaban hace una generación: que la UE patrocinara una economía mixta pública/privada en la tradición progresista del siglo xx. Pero en vez de un "súper Estado europeo" emergente dirigido por representantes elegidos con poder para promover la recuperación económica y el crecimiento refinanciando las deudas a fin de revivir el empleo, la eurozona es dirigida por la troika en nombre de los tenedores de bonos y de los bancos. Los tecnócratas del вCE y la UE sirven a los intereses de los acreedores y no a los de la población, las empresas y los gobiernos cada vez más endeudados. La única integración real ha sido la financiera, y esta ha hecho posible que el всE 
abrogue la soberanía nacional para decidir el gasto público y la política tributaria. Y lo que dictamina es austeridad y contracción económica.

Además de la condonación de deudas incobrables, se necesita una política fiscal expansionista para evitar que la eurozona se convierta en una zona muerta. Pero la UE no ha unificado la política tributaria, y la creación de dinero para financiar gastos deficitarios está bloqueada por la falta de un banco central que monetice los déficits del gobierno bajo el control de funcionarios elegidos. El banco central de Europa no financia gastos deficitarios para revivir el empleo y el crecimiento económico. "Europa ha hecho grandes esfuerzos para crear un 'mercado único' sin ampliar el Estado, mientras pretende que el Banco Central no puede proporcionar dinero nuevo al sistema”. Sin monetizar los déficits, se deben recortar los presupuestos y feriar las empresas de servicios públicos, dejando a los bancos y tenedores de bonos a cargo de asignar los recursos.

Mientras que "el mercado" signifique mantener la alta deuda pendiendo sobre la cabeza, la economía será sacrificada a los acreedores, cuyos títulos de deuda dominarán el mercado y, bajo las reglas de la UE y del BCE, también dominarán el Estado en vez de que este controle el sistema financiero o incluso la política tributaria. A esto Galbraith lo llama guerra financiera totalitaria, y dice que su padre filosófico es Friedrich Hayek y el ancestro político de este bolchevismo de mercado es Stalin. El resultado es una crisis que "continuará, hasta que Europa cambie de opinión. Continuará hasta que las fuerzas que construyeron el Estado de bienestar se levanten para defenderlo".

Para impedir tal reactivación política progresista, la troika promueve un cambio de régimen en las economías recalcitrantes, como juzgó a Syriza por intentar oponerse al compromiso de los acreedores con la austeridad. El aplastamiento de la coalición griega de Syriza se discutió abiertamente en toda Europa como un ensayo general para bloquear el apoyo de la izquierda a sus argumentos. "Los gobiernos de izquierda, sin importar cuán libres de corrupción, sin importar cuán pro europeos - concluye Galbraith- no son aceptables para la comunidad de acreedores e instituciones que conforman el sistema europeo".

A la oposición a la austeridad la llaman "contagio", como si la prosperidad y la mejora del nivel de vida fuesen una enfermedad económica, no la bancarrota nacional forzada por la burocracia del все y de la ue (y el FMI). Para impedir que Podemos en España y partidos similares en Portugal e Italia organizaran la recuperación de la austeridad en la eurozona, estas instituciones financieras apoyan 
gobiernos de derecha mientras aprietan las tuercas a los gobiernos de izquierda. Eso es lo que sucede cuando los bancos centrales se hacen "independientes" de la política democrática electoral y del control parlamentario.

La narración de Galbraith describe mes por mes cómo el FMi y el BCE abrogaron la democracia griega en nombre de los acreedores y los privatizadores. Intentaron socavar el gobierno de Syriza desde el comienzo, convirtiendo a Grecia en un ejemplo práctico para disuadir a Podemos de España y a partidos semejantes de Portugal e Italia de la idea de que se podían oponer al asalto de los acreedores para extraer rentas mediante la privatización y a expensas de los fondos de pensiones y del gasto social. En contraste, han mostrado un favoritismo conciliatorio hacia los partidos europeos de derecha para mantenerlos en el poder contra la izquierda.

A nivel superficial, la "solución" de la troika -pagar a los acreedores desangrando la economía- parece contraproducente. Pero este fracaso aparente parece ser su objetivo real: el remate de los activos del sector público en su versión R2 P: Responsabilidad para Privatizar. Para Grecia esto significa rematar sus puertos, sus islas y sus centros turísticos, la electricidad y otras empresas públicas.

El все у el Fмг aceleraron el colapso económico de Grecia exigiendo aumentar el IVA al 23\%, lo que encareció el turismo en las islas. "El objeto evidente del programa de acreedores es entonces no reformar", señala Galbraith. En vez de ayudar a que la economía pueda competir, "el recorte de pensiones, la reducción de salarios, el aumento de impuestos y las ventas a precios irrisorios se presentan bajo la idea mágica de que la economía se recuperará a pesar de la carga de impuestos más altos, menor poder adquisitivo y repatriación externa de las ganancias de la privatización". Las empresas públicas privatizadas se convierten en 'vacas de efectivo' para que los compradores extraigan rentas de monopolio, elevando el costo de vida y haciendo negocios.

Las políticas de la UE en pro de los acreedores están escritas "en cada tratado europeo, de Roma a Maastricht", e ignoran la "visión del 'crecimiento sostenible' y la 'inclusión social' que pregonan de labios para afuera”. El mandato alemán es reforzar la austeridad monetaria del все e imponer la austeridad fiscal bloqueando la financiación de los déficits presupuestales de otros países (excepto por la flexibilización cuantitativa para salvar banqueros). 


\section{LA GUERRA FINANCIERA EMPRENDIDA POR EL BCE Y EL FMI}

No es así como se suponía que terminaría la UE. Su ideal era poner fin al milenio de conflicto militar europeo intestino. Eso fue bastante fácil, porque la guerra basada en la ocupación de la infantería ya era algo del pasado cuando se formó la uE. Ninguna economía industrial puede hoy montar políticamente la invasión militar necesaria para ocupar otro país, no a Alemania o Francia, Italia o Rusia. Incluso en Estados Unidos, las protestas contra la guerra de Vietnam pusieron fin al servicio militar obligatorio. En el mundo de hoy la guerra puede bombardear y destruir - desde la distancia- pero no puede invadir a un adversario.

E1 segundo argumento para unirse a la uE era que administraría la socialdemocracia contra la corrupción y cualquier repetición de dictaduras de derecha. Pero eso no ocurrió. Todo lo contrario: aunque los tratados de la uE invocan la democracia de labios para afuera, niegan la soberanía monetaria. El FM у la burocracia del все у de la UE han actuado en conjunto para recoger la deuda incobrable que dejó su imprudente operación de salvamento de los tenedores de bonos holandeses, franceses, alemanes, etc. En un comportamiento que recuerda la exigencia de los Aliados a Alemania, en la década de 1920, de altas reparaciones de guerra impagables, sus demandas de pago se basan en la teoría económica basura y depredadora de que la deuda externa de cualquier magnitud se puede pagar imponiendo una profunda austeridad y la privatización a precios irrisorios.

La arena del conflicto y la rivalidad se ha trasladado entonces del campo de batalla militar al financiero. Junto con el FMI y el вCE, los bancos centrales de todo el mundo son conocidos por su oposición a la autoridad democrática para fijar impuestos y regular las economías. La política del sector financiero de dejar la asignación del dinero y el crédito a los bancos y tenedores de bonos exige bloquear la creación de dinero público. Esto deja al sector financiero como planificador central de la economía.

La creación del euro se puede ver mejor como un golpe de Estado legalista para remplazar a los parlamentos nacionales por una camarilla de administradores financieros que actúan en nombre de los acreedores, en su mayoría sacados de las filas de banqueros de inversión. La política tributaria, las políticas regulatoria y de pensiones se asignan a estos planificadores centrales no elegidos. Con poder para abrogar la autodeterminación soberana y los referendos nacionales sobre política económica y social, su receta de política es imponer la austeridad y la privatización a precios de saldo que son básicamente ejecuciones 
hipotecarias contra las economías deudoras. A esto, Galbraith lo llama apropiadamente colonialismo financiero.

La toma de activos promovida por el FM у el вСE es incompatible con la reactivación de Grecia u otras economías de Europa del sur (para no hablar de las bálticas y de Ucrania). La teoría no ha cambiado desde que se impuso a Alemania después de la Primera Guerra Mundial: son las teorías de Jacques Rueff, Bertil Ohlin y los austriacos cuestionadas en su momento por Keynes, Harold Moulton y otros autores ${ }^{1}$. Su papel victorioso en ese debate ha sido expurgado del discurso público actual e incluso de la academia. Lo que hoy pasa por ortodoxia económica es la economía de la austeridad no reforma$\mathrm{da}$ (e incorregible) de los años veinte, la cual pretende que todas las deudas de una economía se pueden pagar simplemente reduciendo el nivel de salarios, gravando más a los consumidores, empobreciendo más a los trabajadores (y, en últimas, a las empresas y al gobierno) y malvendiendo las empresas públicas (principalmente a extranjeros de las naciones acreedoras).

Galbraith compara a los economistas con los médicos, cuyo lema profesional es "No hagas daño". Los economistas no pueden evitar dañar a las economías cuando su prioridad es salvar de pérdidas a banqueros y tenedores de bonos desangrando las economías para pagar a los acreedores. Lo que el FMi llama "programas de estabilización" impone una espiral descendente de deflación de la deuda y ampliación de los déficits fiscales. Esto obliga a los países a malvender sus tierras y sus minas, los edificios públicos, las empresas públicas de electricidad, telefonía y comunicaciones, las carreteras y autopistas.

A primera vista el repetido "fracaso" de las recetas de austeridad para "ayudar a que las economías se recuperen" parece ser una locura, definida como hacer lo mismo una y otra vez, esperando que el resultado sea diferente. Pero, ¿y si los planificadores financieros no están locos? ¿Qué ocurre si solo buscan éxito profesional racionalizando la política que alientan los intereses creados que los utilizan, encabezados por el FMI, los banqueros centrales y los grupos de expertos en política y las escuelas de negocios a los que patrocinan? Los efectos de las políticas en pro de los acreedores han sido tan constantes durante tantas décadas que hoy se deben considerar deliberadas y no un error que se pueda reparar invocando una visión más realista de la economía (de la cual ya se disponía en los años veinte).

${ }_{1}$ Mi libro Trade, development and foreign debt (2002) revisa el debate de las reparaciones alemanas sobre "transferencias de capital" con respecto al modo en que la austeridad reduce la capacidad de pago. 
Teniendo en cuenta la mentalidad de la eurozona, Galbraith pregunta si Grecia puede estar mejor actuando a solas, fuera del "hospicio” FMI/BCE y sus curanderos financieros. Salvar la economía exige rechazar las demandas de austeridad que hacen los acreedores a través de los planificadores centrales del FMI, el вCE y otras organizaciones internacionales.

Una nación soberana tiene derecho a no ser empobrecida por acreedores que le han prestado sumas muy superiores a las que puede pagar sin verse forzada a incurrir en privatizaciones a precios irrisorios. Esas exigencias son semejantes a un ataque militar, que tiene un objetivo similar: apoderarse de las tierras, los recursos naturales y la infraestructura pública de la economía endeudada, y controlar su gobierno.

Tales exigencias son contrarias a la democracia parlamentaria y a la autodeterminación nacional. Pero están escritas en la manera como se construyó la eurozona. Por ello, la retirada del régimen financiero actual es una precondición para recuperar la soberanía económica. Se debe comenzar con el control de la oferta monetaria y del sistema tributario, seguido por el control de la infraestructura pública y de la fijación de precios de sus servicios.

\section{EL FUTURO DE LA IZQUIERDA EUROPEA}

Lo que llevó a los gobiernos (aunque no a todos los electores) a aceptar una autoridad paneuropea supranacional fue el trauma de la Segunda Guerra Mundial. Parecía que los Estados-nación eran propensos a hacer la guerra, y que los Estados Unidos de Europa no combatirían, al menos no entre sí. Pero la autoridad que se ha establecido es financiera, en pro de los acreedores y contraria al trabajo, con poder para imponer la austeridad y convertir lo que es de dominio público en monopolios privatizados.

La UE no se puede "arreglar" con reformas marginales. El tratamiento de Grecia muestra que se debe remodelar; de lo contrario, los países empezarán a retirarse para restaurar la democracia parlamentaria y mantener lo que les queda de soberanía. El ideal del sector financiero es el de economías centralmente planificadas por los banqueros, sin infraestructura pública que no se haya privatizado. Las economías privatizadas deben ser financiarizadas para aprovechar las oportunidades de extraer rentas de monopolio.

Se ha arrojado el guante y hoy se plantea una pregunta semejante a la de los años treinta: ¿la alternativa a la austeridad, la deflación de la deuda y la quiebra económica resultante será obra de una opción 
socialista en pro del trabajo, o llevará a una victoria de los partidos de derecha anti europeos?

Lo que hace diferente la situación es el alto grado en que los partidos europeos que hoy se autodenominan socialistas, socialdemócratas o laboristas han aceptado la privatización y la oposición a los déficits presupuestales. Este cambio invierte lo que impulsaban en sus orígenes hace más de un siglo. De modo que el problema no es tan solo oponerse a la derecha del espectro político, es reconstruir una verdadera izquierda europea.

El libro de Galbraith tiene importantes implicaciones para las políticas necesarias para evitar que la eurozona se convierta en una zona muerta siguiendo las líneas de la desastrosa historia del "éxito" oligárquico de Letonia (en pocas palabras, el "milagro Báltico" es una fuerte emigración y un drástico declive de los salarios después de impuestos).

Si la izquierda europea no logra crear una alternativa a la austeridad de la eurozona, los nacionalistas de derecha dirigirán la campaña de retirada. Amanecer Dorado en Grecia, el Frente Nacional en Francia, los partidos nacionalistas en Hungría, Austria y Polonia y el Partido por la Independencia del Reino Unido están intentando llenar el vacío que dejó la ausencia de una alternativa socialista a la financiarización bajo el dirigismo del все у del Fмі. 